\title{
Affordable and Sustainable Housing Option for Rural Development
}

\author{
Prof. Nisha Thakur \\ Asst. Prof., Civil Engg. Department, \\ D.M.I.E.T.R., Wardha, India \\ Prof. Snehal Metkar \\ Asst. Prof., Civil Engg. Department, \\ A.S. Polytechnic, Pipri, Wardha, India
}

\begin{abstract}
India is rapidly developing country. The economics of the government identify the building industry as a vital engine of economic growth. The advancement in the field of technology have influenced environment to a great extent. The rising need of housing for the growing rural and urban population is a pressing issue. To maintain rapid rates of economic growth in the 21 st century, it is important to put strategy for urban and rural housing to meet the needs of the rural and urban population. Straw bale construction can be one of the best alternative for the country like India where agriculture is still the main source of income and production of straw is tremendous. Also the use of straw in building will solve the problem of pollution caused by burning of straw. Straw bale are renewable resources having tremendous features as cost effective with high health value, aesthetics value, thermal performance, fire resistance, light in weight and eco-friendly in nature. This paper takes an overview of application of straw bale for construction of rural housing with an aim to reach an economic and environmentally adopted system for wide application of straw bale construction in India.
\end{abstract}

Keywords: Straw bale, high health value, aesthetics value, thermal performance, fire resistance

\section{I.INTRODUCTION}

Straw often being an agricultural surplus by-product and, it's inexpensive, and an easily renewable medium. Straw is an agricultural by-product; the dry stalks of cereal plants, after the grain and chaff have been removed. Straw makes up about half of the yield of cereal crops such as barley, oats, rice, rye and wheat. Straw bale is a bundle of straw tightly bound with twine or wire. Bales may be square, rectangular, or round, depending on the type of baler used. Bale density varies according to the type of grains, moisture level and degree of compaction provided by the baler[1]. Properly built, straw bale structures are fire-resistant, waterproof and actually pest free, with superinsulated walls. Each year tons of straw remains as a by-product of the agricultural crops of wheat, rice, rye, corn and grass seed. This straw is generally left to compost in the fields or is burned. The burning of agricultural straw is a significant cause of air pollution and contributes to global warming. The straw-bale house was first seen simply as a make-shift structure, to provide temporary lodging, until enough funds were available to pay for the shipping in of timbers, to build a "real" house. Actual straw-bale construction was pioneered in Nebraska in the United States, in the late 19th/early 20th century[2]. However, these homes proved to be comfortable, durable, and affordable, and so became regarded as permanent housing. Over the past quickly century they have indeed outlived many neighbouring timber-frame buildings and a number are in continuing use today and beginning their second century. Building with straw bales is slowly but surely gaining ever wider acceptance across America, Europe and Australasia. In many instances government bodies actively welcome sustainable building projects and straw bale building is readily recognized as a sustainable building method. Straw bale construction can be one of the best alternative for all kind of people for constructing a economic building with a sustainable material. 


\section{AVAILABILITY OF STRAW}

Because of the large quantity of straw available, and their tensile qualities, many types of agricultural straw are ideal for a wide array of products including paper, building materials, textiles and other fiber-based products. Where storage of agricultural straw was once a limiting factor in its supply, modern harvest methods support year-round storage thus facilitating a ready and available supply of the fiber. The table below indicates the quantity of agricultural byproduct available for use with India being the second highest producer of rice straw and wheat straw in the world.

Table 1: Ranking of Rice Production Countries

\begin{tabular}{|c|c|c|}
\hline Rank & Area & $\begin{array}{l}\text { Rice Production } \\
\text { (Metric Tons) }\end{array}$ \\
\hline 1 & China & 197212010 \\
\hline 2 & India & 120620000 \\
\hline 3 & Indonesia & 66411500 \\
\hline 4 & Bangladesh & 49355000 \\
\hline 5 & Viet Nam & 39988900 \\
\hline 6 & Myanmar & 33204500 \\
\hline 7 & Thailand & 31597200 \\
\hline 8 & Philippines & 15771700 \\
\hline 9 & Brazil & 11308900 \\
\hline 10 & USA & 11027000 \\
\hline 11 & Japan & 10600000 \\
\hline 12 & Cambodia & 8245320 \\
\hline 13 & Pakistan & 7235000 \\
\hline 14 & Republic of Korea & 5804000 \\
\hline 15 & Madagascar & 4737970 \\
\hline 16 & Sri Lanka & 4300620 \\
\hline 17 & Egypt & 4329500 \\
\hline 18 & Nepal & 4023820 \\
\hline 19 & Nigeria & 3218760 \\
\hline 20 & Peru & 2831370 \\
\hline
\end{tabular}

Table 2: Ranking of Wheat Production Countries

\begin{tabular}{|c|c|c|}
\hline Rank & Area & $\begin{array}{c}\text { Wheat } \\
\text { Production } \\
\text { (Metric Tons) }\end{array}$ \\
\hline 1 & China & 115180303 \\
\hline 2 & India & 80710000 \\
\hline 3 & USA & 60102600 \\
\hline 4 & France & 38207000 \\
\hline 5 & Russia Federation & 41507600 \\
\hline 6 & Pakistan & 23310800 \\
\hline 7 & Canada & 23166800 \\
\hline 8 & Australia & 22138000 \\
\hline 9 & Turkey & 19660000 \\
\hline 10 & Argentina & 14914500 \\
\hline 11 & Germany & 24106700 \\
\hline 12 & Iran & 15028800 \\
\hline 13 & Ukraine & 16851300 \\
\hline 14 & United Kingdom & 14878000 \\
\hline 15 & Kazakhstan & 9638400 \\
\hline 16 & Egypt & 7177400 \\
\hline 17 & Brazil & 6036790 \\
\hline 18 & Poland & 9487800 \\
\hline 19 & Uzbekistan & 6730400 \\
\hline 20 & Italy & 6900000 \\
\hline
\end{tabular}

\section{CHARACTERISTICS OF STRAW BALE}

The thick walls (typically 21 to 26 inches $(530 \mathrm{~mm}$ ) when stuccoed/plastered), result in deeper window and door "reveals", similar to stone and adobe buildings. Since the bales are irregular and may be shaped easily, they are readily adaptable to curved designs, and when plastered, tend toward a relaxed, imperfect texture and shape. If flat, straight walls are desired, this can be achieved, as well, by the application of more plaster[3].

1. Acoustics

2. Insulation

3. Thermal mass

4. Passive solar

5. Availability, types and cost

6. Resistance to pests

7. Resistance to fire

8. Structural properties

9. Design and construction challenges 


\subsection{Acoustics of Straw Bale Structures}

A report carried out in Denmark measured the sound insulation horizontal strawbales (where the straws were perpendicular to the plane of the wall) performance of a wall in an existing home. The measurements were carried out in a wall with both and on a wall with vertical strawbales (where the straws were parallel with the plane of the wall). In both instances there were approximately $40 \mathrm{~mm}$ of clay rendering on eachside of the wall. The results shows that straw bale-walls will have satisfactory sound insulation performance. Within a dwelling the sound reduction is particularly satisfactory and the actual sound insulation will most likely be determined by the doors.

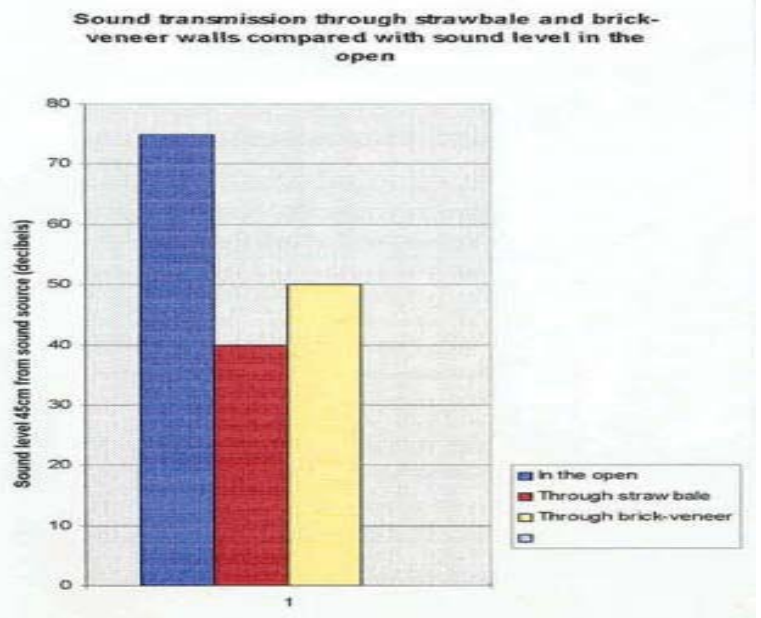

Fig.1: Graph showing the transmission of sound through wall compared with sound levels in the open.

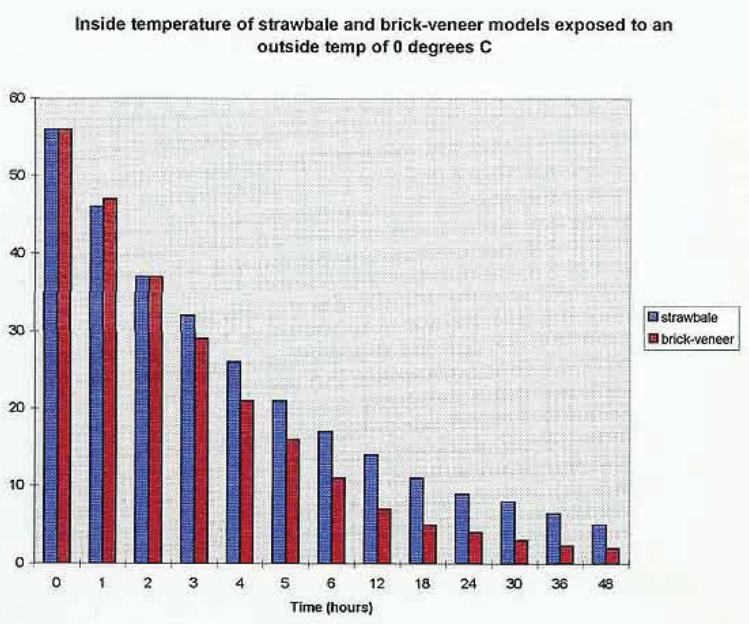

Fig.2 Graph showing the temperature in the strawbale two types of model showing the superior insulation quality of straw. (Courtesy: http://www.foodforest.com.au/fact sheets/building-with-strawbales/strawbale-history-and-facts/)

\subsection{Insulation}

A carefully constructed straw-bale building has excellent thermal performance because of its combination of the bales' high insulative value and the thermal mass provided by the interior's thick plaster coating. A good starting point is a discussion of what R-value is, and what it is not. It is not an absolute measure of how energy efficient your building is. It is not even a perfect way of predicting the wall's contribution to thermal comfort. It is one piece of information about the wall that, with other information, can enable you to estimate the heat loss and heat gain through the walls. $R$-value is the inverse of $U$-factor $(R=1 / \mathrm{U})$. U-factor is a measure of thermal conductance, or how easily a material (or system) allows heat to pass through it. This is how U-factor is defined (in the U.S.): the number of British thermal units that pass through one square foot of a material (or system) per hour with a one degree Fahrenheit temperature difference between the two sides of the material. Mathematically: $U=(B t u / h \times a \times F)$ $B t u=$ British thermal units, $a=$ area in square feet, $F=$ temperature Fahrenheit. In most other countries U-factor is defined in terms of Watts per square meter per Kelvin[W/(m2*K)]. To convert metric (SI) U-factors to inch-pound (IP) U-factors multiply by 0.1761 ; to convert the other way, simply divide by 0.1761 . To convert IP R-values to metric R-values, multiply by 5.6783 .

\subsection{Thermal Mass}

Thermal mass reduces temperature swings due to day time warming and night time cooling, by absorbing and then gradually releasing heat. This can result in a direct reduction in the need for fuel or electricity to regulate temperature, and indirectly in savings through lifestyle adjustments: occupants of a moderate environment, with only gradual temperature swings, are less likely to use artificial heating and cooling. This is most easily achieved at high desert altitudes where a clear sky contributes to both warm days (solar gain) and cool nights (nighttime cooling), but the principle still works in other climates as well. Straw bale like all other organic insulation materials are better able to buffer heat then inorganic insulation. Basically this improves thermal comfort within a building, exterior temperature swings are delayed and damped. Having thermal mass is the difference between the interior comfort experienced within a catherderal or in a corrugated shed, either in the summer or winter. The fact that a straw bale wall should be plastered on innner and outer surfaces greatly enhances the heat buffering effect by substantially adding to the thermal mass of the building. The combination of insulation with sufficient thermal mass creates the high level of comfort experienced in most straw bale buildings. Adding extra thermal mass by even 
thicker plaster layers on inner surfaces encounters the effects of diminishing returns. Doubling the thickness over $35 \mathrm{~mm}$ (which seams to be the optimum) increases comfort by an insignificant amount.

\subsection{Passive Solar}

To improve the energy efficiency of houses is increasingly becoming the design challenge of the $21^{\text {st }}$ century. Passive solar refers to buildings designed to maximise the heating and cooling effects of the environment around them. They are called passive because there are none (or few) parts of the design that require energy to operate. The most common technique for passively taking advantage of the environment is maximising solar gain by exposing interior surfaces to the suns warmth and then designing the building to best contain that warmth. At the other end of the scale, where climates are hot and passive cooling is what's needed, one technique is using rising warm air to draw basement cooled air up through a building. It should be stressed that straw bale homes are not inherently good for passive solar gain, they need to be designed to make use of it, it doesn't just happen. The same is true of any building material or system. Following are the basic features that distinguish straw bale buildings designed to maximize passive (think of free and sustainable) heating and cooling:

- Limited exterior wall surface with high insulation.

- Equator-facing, East and West Roof overhangs correctly sized to block the summer sun (angle) and still allow the lower winter sun angle to provide heating of interior thermal Mass.

- Passive preheating/precooling of external air by drawing through cellers, porches, glass houses and heat exchangers

\subsection{Type \& Cost of Bale}

Types-Bales are rectangular compressed blocks of straw, bound by strings or wires. Straw bales come in all shapes and sizes. Rectangular bales are the only bales suitable for building. Different styles and opinions have grown up around the world as bale building has spread. What was suitable in one climate has not proved to be best practice in others, and availability and cost of materials varies from country to country. Cost depends upon time of purchase(harvest months) of the bales, how far they need to be transported, and type of bale - whether it's wheat straw, flax straw, or rice straw. Different "waste" products have different values for farmers and some are less usable than others for agricultural purposes.

\subsection{Resistance to Pests}

Straw bales are thick and dense enough to keep out many kinds of pests. As well, the outer layer of plaster makes them unattractive or impenetrable to animals and insects. Finally, because straw contains little nutrient value to most animals and insects, it does not attract pests. Straw bales are thick and dense enough to keep out many kinds of pests. As well, the outer layer of plaster makes them unattractive or impenetrable to animals and insects. Finally, because straw contains little nutrient value to most animals and insects, it does not attract pests. Termites like moist damp conditions. While a wall is kept dry, there is little danger termites would have any interest. When termites do manage to enter a wall, they tend to bypass the straw and attack any wooden studs. Plastered surface with no openings prevent the structure from infestation.

\subsection{Resistance to Fire}

Although loose straw is quite flammable, once packed into a bale it is too dense to allow enough air for combustion22. By analogy, it is easy to light a single piece of paper on fire, but difficult and time consuming to burn an entire phone book. In construction it is critical to have, at a minimum, a parge coat of plaster on all surfaces of the wall. Parge coating the wall involves troweling on a thin coating of mortar and brushing it smooth. Typical failure of straw-bale homes involves frame walls set against straw-bale walls without a parge coat. A spark from an electrical short or an error by a plumber ignites the hair-like fuzz on the exposed bale. The flame spreads upward and sets the wood framing on fire causing the wood framing to burn. The typical fire results in little fire damage to bales, but extensive water damage due to the fire suppression activities. The ASTM E-119 fire resistance test for plastered straw-bale wall assemblies in 1993 passed for a 2 hour fire-wall assembly. In this test a gas flame blows on one side of the wall at approximately 2000 degree Fahrenheit (1100 degrees Celsius) while the temperature of the other side of the wall is continuously measured. The results of this test had no burn-through and a maximum temperature rise of 60 degrees Fahrenheit (33.3 degrees Celsius).

\subsection{Structural Properties}


There are two primary forms of straw bale construction, load bearing and non-load bearing (post and beam). In load bearing structures (commonly known as the Nebraskan style), the weight of the roof and lateral shear pressures are actually carried by the bales and the plaster which encases them. This is an easy load for straw bales each of which can withstand up to 15,000 pounds of vertical pressure when laid flat. In non-load bearing (commonly known as post and beam method) straw bale construction, a frame is first built out of wood, and the bales serve as an in-fill insulation. The advantage of this type of structure is that inspection officials recognize and understand this process, and it provides a roof structure under which to build up straw bale walls. Load-bearing straw-bale walls are typically used only in single-storey or occasionally double-storey structures. Post and beam straw-bale structures have been used for buildings as large as 14,000 square feet $(1,300 \mathrm{~m} 2)$.

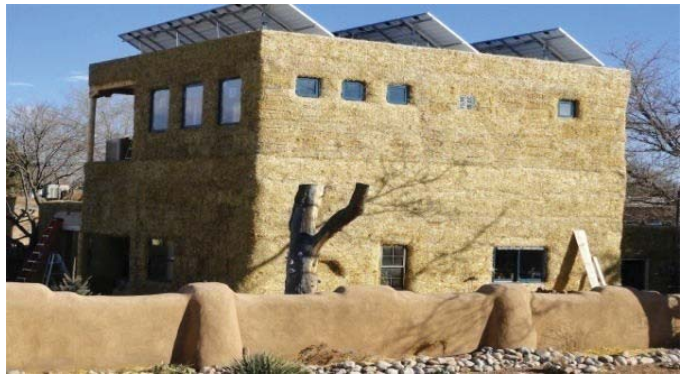

Fig. 1: Load Bearing Straw-bale Walls

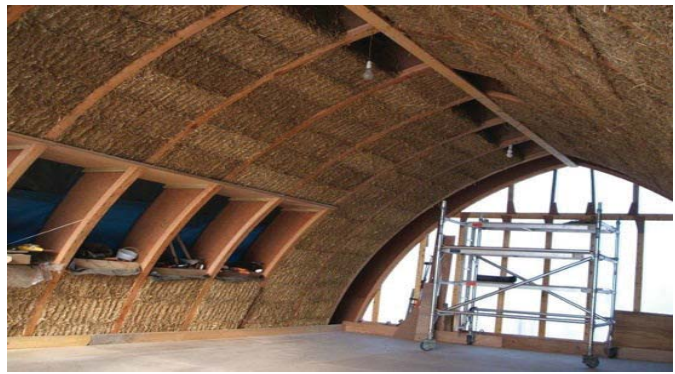

Fig. 2: Non Load Bearing Straw-bale Walls

\subsection{Design and Construction Challenges}

Straw-bale construction is still considered experimental in many jurisdictions. Building codes may not include it, local authorities may not recognize it, and most contractors will probably not be experienced in its use. Straw-bale buildings must be carefully designed to eliminate the possibility of moisture entering the walls, especially from above. Successful designs often incorporate roof overhangs that are wider than normal and roof shapes and detailing that minimize the risk of water splashing against walls. Because straw-bale walls are much thicker than normal walls, there is sometimes a compromise between the size of the building's footprint and the amount of living space.

\section{STRAW BALE AS BUILDING MATERIAL}

Straw is appealing as a building material for several reasons. In areas of grain production, straw is inexpensive. The quality of lumber is dropping, prices are unpredictable, and some suggest future supplies may be limited. Straw is a secondary waste material from grain production; its embodied energy should be fairly low. since grain farming is common across most cultures and regions. This fact alone is enough to move towards using this abundant renewable resource for construction purposes, even if it held no particular advantage over other building materials. A well built wall creates an unbroken wall of high insulation. Also materials used to create bale walls are less expensive than other common wall systems. Straw bale construction is owner-builder friendly because the wall raising is easily done, thus cutting down on labor costs. Straw bale houses have demonstrated overwhelming results; fire and earthquake resistance, extremely high heat and sound insulation values, almost ten times as much as wood and bricks, energy efficient, and require minimum maintenance. All these advantages in favor of straw bale construction cumulate significant cost advantage compared to conventional building techniques with bricks or wood. The field baler is recent introduction in India for recovery of combine-harvested straw for its utilization either as animal feed or by paper and board making industries. The bale assembly can do a number of things, depending upon the structural design of the building: resist tipping. Keep out the wind; inhibiting air/moist Holds itself up, be self-supporting and ure infiltration. Resist heat transfer (insulation) Reduce water intrusion and migration, store and transfer moisture within the wall. Keep the assembly from buckling, under a compressive load. Keep the assembly from deflecting in a strong wind. Keep the assembly from bursting apart in an earthquake, when pushed and pulled from all directions. Hold the plaster at least while it's curing. Keep the plaster from cracking after it is cured, from shrinkage or movement. Transfer and absorb loads to and from the plaster. Support the plaster skins from buckling. Support the roof load (compression). Reduce damage or failure from high winds (ductility). Reduce damage or failure from earthquakes (ductility). Stop bullets and/or flying debris. Structural analysis has shown that the straw-bale/stucco assembly behaves much like a sandwich panel, with the rigid stucco skins initially bearing most of the load and adding considerable strength to the wall. 


\section{DISADVANTAGES}

The straw must be kept dry throughout the whole building process until it is plastered. This can be very difficult on a large building, or one that is being constructed slowly. Openings for windows and doors must not exceed $50 \%$ of the wall surface area in any wall. Maximum unsupported (unbraced) wall length is $6 \mathrm{~m}\left(20^{\prime}\right)$. Greater technical ability is required to make the structure stable whilst the straw is being placed. It requires a high level of carpentry skill (or metalwork experience in the case of a steel frame) to construct the frames. It uses a large amount of timber. Requires technical know-how for electrical and plumb-ing installations and execution .Short term training workshops can create awareness to common man and labour regarding installation and maintenance of the structure. Job specific and site specific detail suggestions by the designers will increase the popularity of this material. - Typical failure of straw-bale homes involves frame walls set against straw-bale walls without a mortar coat. A spark from an electrical short or an error by a plumber ignites the hair-like fuzz on the exposed bale. The flame spreads upward and sets the wood framing on fire causing the wood framing to burn. The typical fire results in little fire damage to bales, but extensive water damage due to the fire suppression activities. Further innovations and improvements in this field of Sustainable construction practices is thus encouraged from the future architects so as to make use of this abundantly available resource efficiently in rural and suburban context.

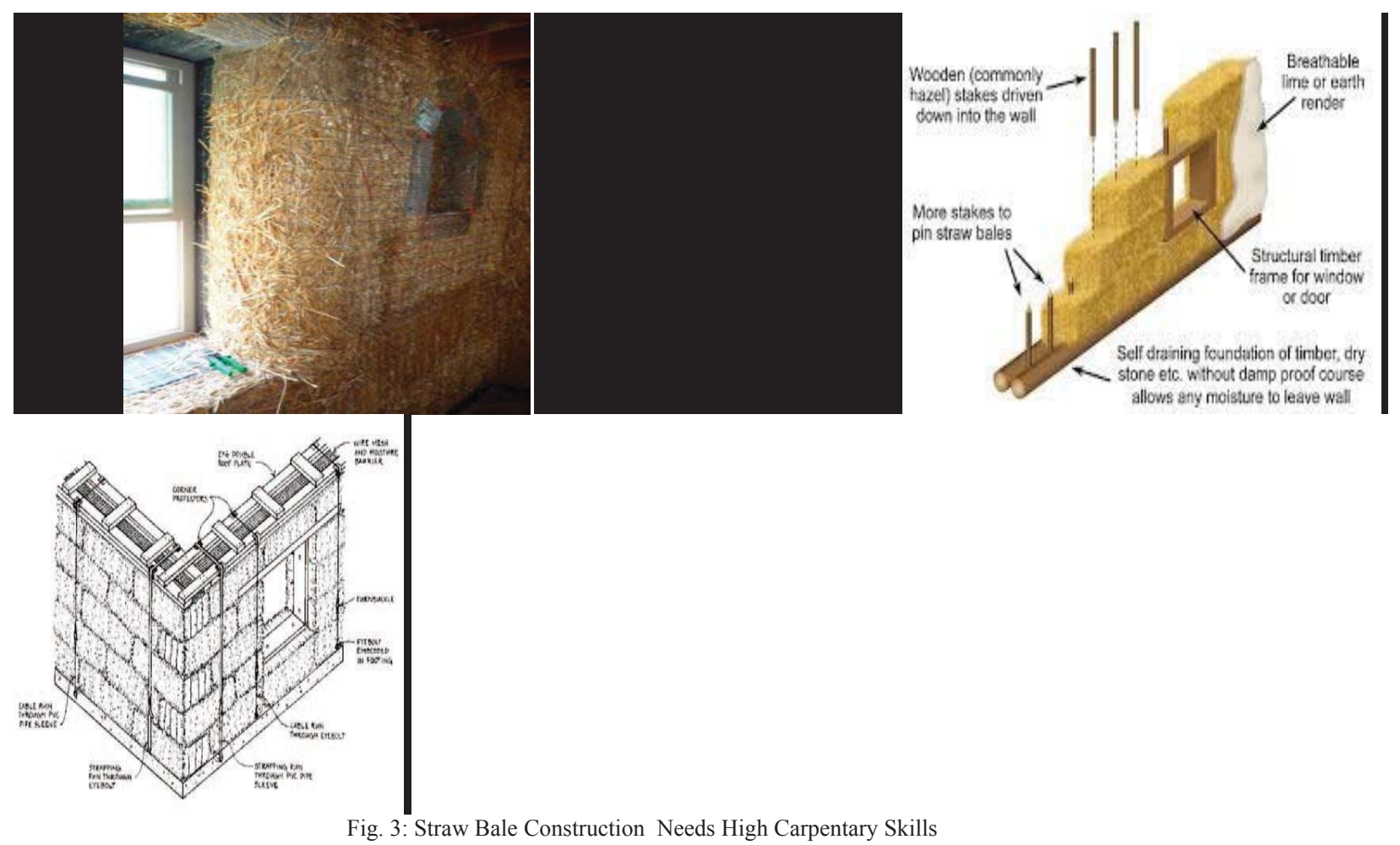

\section{FINISHES}

Straw-bale walls are most typically plastered on the outside with lime, clay, or a cement and lime mix. Inside surfaces are typically lime, clay, plaster board (gypsum) or Structolite, a US Gypsum product that is formulated for thick applications (Wanek, Catherine52). Structural analysis53 has shown that the straw-bale/stucco assembly behaves much like a sandwich panel54, with the rigid stucco skins initially bearing most of the load and adding considerable strength to the wall. An important consideration when choosing a finish is that the outside surface of the walls must be more permeable to moisture than the inside surface. Failing to follow this rule will result in moisture accumulating in the wall, which will eventually rot the bales, just as it would rot anything untreated. As two extreme examples, if you chose to finish the inside surface with cement plaster and seal it with acrylic or latex paint, then any moisture in the wall can effectively only move outwards (assuming that's not also painted). If you did 
the opposite and used natural finishes on the inside but painted the outside with plastic paint then you are trapping moisture into the walls and rotting is likely.

\section{Cement/ Sand Stucco}

Stucco for straw-bale walls can be cement/sand-based, although mixes containing earth or clay and/or with a high percentage of lime, replacing part or all of the cement are increasingly popular trends. (Advocates of sustainable construction are becoming increasingly concerned with the fact that for every ton of cement manufactured and used, another ton of climate-changing fossil CO2 is released into the atmosphere.) Avoid cement stucco on bale structures. Cement is not breathable. Humidity - the arch enemy of any straw bale construction- will accumulate inside bales covered in cement stucco.

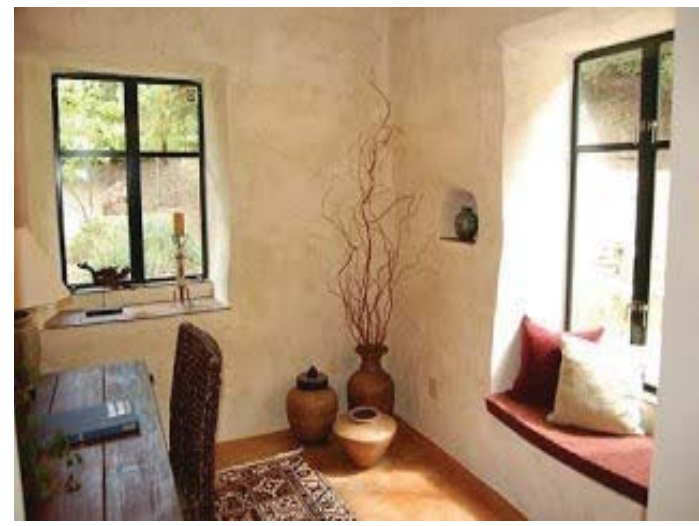

Fig. 4: Sand Base Plaster

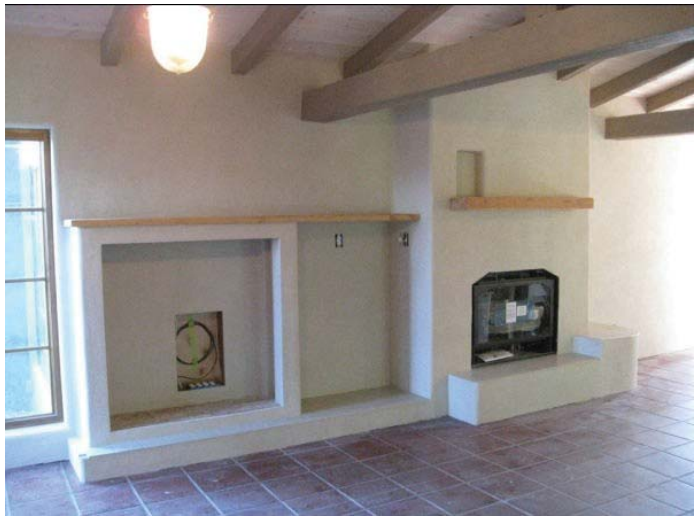

Fig. 5 : Clay Plaster

\section{Clay plaster}

Clay plaster allow higher water vapour permeability through the walls than lime plaster, which in turn is much more than cement plasters. This means the right type of wall will dry quickly when wetted by rain and will effectively transfer any moisture which accumulates in the wall, whether from a leak or from normal day-to-day living (a significant amount). Clay plasters are great regulators of the indoor climate, they 'breath', which means moisture is absorbed and released - it does not mean that air trickles through the wall. On the inside of a house this property makes it well suited to damp areas like kitchens and bathrooms, it will absorb periodic moisture and to some extent odour, and slowly release it again. Clay plaster typically is quite thick it also serves to regulate temperature by warming and cooling quite slowly. On the outside of the house this effect can even mean that the clay will wick (pull) moisture out of the straw and release it to the exterior Air.

\section{Lime Plaster}

Performs in a similar way to clay plaster. Lime plasters consist of Lime, aggregate and other additives. Lime plasters are more resistant to weather, mold and impact than clay plasters, but are more time consuming and challenging to finish. A good compromise between breathability and water resistance, they are an ideal outside finish for a house, while clay plasters are more appropriate for the inside.

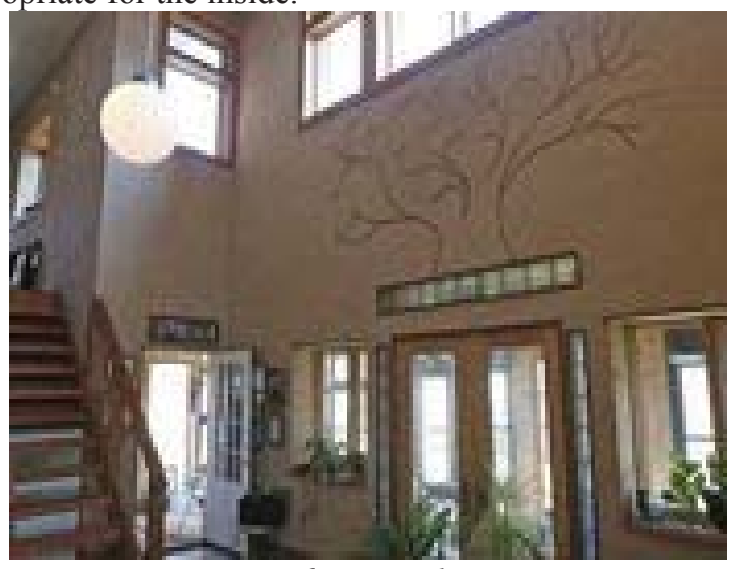

Fig. 6: Lime Plaster 


\section{Tadelakt}

This bright, waterproof lime plaster can be used on the inside of buildings and on the outside. It is the traditional coating of the palaces, hammams and bathrooms of the riads in Morocco. It is characteristically polished with a river stone and treated with a soft soap to acquire its final appearance. Tadelakt has a soft appearance with undulations due to the work of the stone; it is water-tight, which also makes it suitable for making bathtubs and wash basins and confers great decorative capacities. Tadelakt is generally produced with lime of the area of Marrakesh, but other types of lime can also be appropriate.

\section{CONCLUSIONS}

In this emerging world where the rising need of housing is increasing day by day due to tremendous growing of rural and urban population has been a pressuring issue. Without compromising affordability, quality and maintaining the component of earth system has been a challenging task where Straw Bale can be one of the promising building material that meet the overall housing need and energy efficient goal of most of the developing countries like India, Nepal, Bhutan etc where agriculture act as the backbone of development. Although straw can be used in many industries and can save a lot of money, the reason why it is not being widely used is mainly in construction industry is due to lack of peoples awareness. Surprisingly, countries such as India and China who are the worlds' largest cultivators of rice \& wheat, but most of those is considered as waste and limited are only used for productive type but if we can utilize them for construction in the form of straw bale then staying in good house won't be limited to dream for people. Thus awareness regarding straw bale construction should be enhanced in developing countries land agriculture countries like India for effective implementation of straw bale house.

\section{REFERENCES}

[1] http://en.wikibooks.org/wiki/\%2FAcoustics

[2] http://en.wikibooks.org/wiki/\%2FInsulation

[3] http://en.wikibooks.org/wiki/\%2FThermal\%20mass

[4] http://en.wikibooks.org/wiki/\%2FPassive\%20solar

[5] http://en.wikibooks.org/wiki/\%2FAvailability\%20types $\% 20$ and $\% 20$ cost

[6] http://en.wikibooks.org/wiki/\%2FResistance $\% 20$ to\%20pests

[7] http://en.wikibooks.org/wiki/\%2FResistance $\% 20$ to $\% 20$ fire

[8] http://en.wikibooks.org/wiki/\%2FStructural\%20properties

[9] http://en.wikibooks.org/wiki/Category $\% 3$ AStraw $\% 20$ Bale $\% 20$ Construction

[10] www.masterbuilder.co.in

[11] http://en.wikibooks.org/wiki/User:David_Elfstrom 12

[12] http://en.wikibooks.org/wiki/User:DuLithgow

[13] Mark C. Tatum, MSEE, PE “Straw Bale Construction and Building Codes “, Auburn University ,Auburn,Alabama

[14] Halmhuse - Udformning og materialeegenskaber Straw_Bale_Construction/ Resources/Technical_Studies1 [3] Roberts C. 2002. A House of Straw: A Natural Building Odyssey. Chelsea Green Publishing Company.

[15] Bruce King, PE, "Load-Bearing Straw Bale Construction”, Ecological Building Network, 2003. [5] Bruce King1, "Agricultural ByProducts in Construction", Ecological Building Network, 2010.

[16] Garas G., Allam M. and El Dessuky R, "Straw Bale Construction As An Economic Environmental Alternative - A Case Study"

[17] Summers M.D., Blunk S.L. and Jenkins B.M. 2003. How straw decomposes. EBNet Straw Bale Test Program. http://www.ecobuildnetwork.org.

[18] Garas G.L., Wahaba A.S., Hadid M.A., N.M. Farag and Dessuky R. 2008. Adaptation of straw bale building techniques to the Egyptian environmental conditions. Proceeding of the $3^{\text {rd }}$ International Conference of Engineering Research Division onTEngineering Sciences and Technologies, NRC-Cairo-Egypt. March.

[19] Renewable energy and sustainable living fact sheets. 1999. Straw Bale Construction. Midwest Renewable Energy Association. http://www.the-mrea.org

[20] D. A. Bainbridge. Straw Bale Building Resources Brainbridge. Sustainable Management Alliant International University, San Diego, CA. 